\title{
STRUCTURAL DIFFERENCES BETWEEN THE ECONOMY OF BULGARIA AND THE ECONOMICS OF PART OF THE MEMBERS OF THE EUROPEAN UNION
}

\author{
S. Kalinkova* \\ Department "Marketing and Strategic Planning", University of National and World Economy - Sofia, \\ Bulgaria
}

\begin{abstract}
The development of Bulgaria's economic system is often associated with the perception of the idea for "catch up development". Such a concept could not be implemented successfully if there is no information about what this economic system should aim for. For this reason, the main purpose of the study is to outline the structural differences between the economy of Bulgaria and some of the countries of the European Union. In the study it is used the method of the coefficient of structural differences, which is developed by Kiril Gatev. The main research tasks to be considered in the study are: revealing the essence of the coefficient of structural differences and the information that it provides; to assess the degree of "proximity" between Bulgaria and the surveyed countries using the coefficient of structural differences and last but not least, on the basis of the assessments received, to draw conclusions. As a result of the study there will be information about the development of the Bulgarian economy, measured by the elements of the vector of the final consumption, compared to some of the European countries with similar characteristics.
\end{abstract}

Key words: economy, economic system, catch-up development, economic structures

\section{INTRODUCTION}

When examining the development of complex systems, processes and phenomena characterized by an internal structure, it is necessary to have appropriate measures for assessing the strength and direction of the changes in the structures. The on-going changes and complications of economic systems call for a transition to the use of a methodological approach to study structural changes (differences) and irregularities (specialization, concentration). At the core of this approach is the notion of "distance" and the possibility of decaying the general structural change in factor influences. That's why as a first research task it is necessary to reveal the essence of the measurement method that is used in the survey.

\footnotetext{
*Correspondence to: Sabrina Vasileva Kalinkova, Department "Marketing and Strategic

Planning”, University of National and World

Economy - Sofia, Bulgaria; Bulgaria, Bankya, 1320, str. Al. Stamboliyski 1, e-mail:

s.kalinkova@unwe.bg; GSM:0883 306862
}

Switching from a statistical population to a statistical structure makes it possible to remove the type of units used. The statistical structure is a statistical concept, meaning the internal structure of a statistical aggregate, quantified by the relative shares of the parts in the whole.

The individual relative shares meet the conditions:
1) $\sum_{i=1}^{n} f_{i}=1$
$f_{i} \geq 0$
$i=1,2, \ldots, n$

where $f_{i}$ is the $i$-th relative share of $n$-mer statistical structure $\mathrm{F}$.

The possibility of distance being used as a measure of the degree of difference between the compared structures considered as points in the n-measure Euclidean space is examined by Prof. Zdravko Sugarev (1). The use of the angle $\alpha$ for the same purposes is considered by Garabed Minasyan (2).

Among the most widely used summary measures for structural differences are the measures, systematized by Prof. Kiril Gatev 
(3): "The Difference Index; the index of the relative structure; the linear coefficient of absolute structural changes; the integral coefficient of structural changes; as well as the Euclidean distance (d) and angle $\alpha$ ”.

In the present study for the measurement of structural changes is used the integral coefficient of structural differences of prof. Kiril Gatev. The integral coefficient of structural differences is calculated by the formula (2):

2)

$$
K_{D}=\sqrt{\frac{\sum_{i=1}^{k}\left(v_{i 1}-v_{i 2}\right)^{2}}{\sum_{i=1}^{k} v_{i 1}^{2}+\sum_{i=1}^{k} v_{i 2}^{2}}}
$$

where:

$\mathrm{v}_{\mathrm{i} 1}$ - share of the research sector in

2000

$v_{i 2}$ - the share of the research sector in

2013

The integral coefficient for measuring structural differences is used in terms of aggregate economic indicators (volume of total output, volume of output, volume of intermediate production, volume of value added, volume of accumulation, and volume of output for export).

As a result of using the integrated coefficient of structural differences and the obtained assessments on its basis, there will be information about the existing "proximity" between Bulgaria and the other studied countries.

The information for each of the countries is provided by Eurostat in so called supply and use tables - part of the input-output model. These two types of tables were used by the author to construct the symmetric inputoutput table. The data in these tables represents the situation in one national economic system by sectors of that economy. And more, in the table the total amount of goods that is produced in the country is "divided" in two directions: for intermediate consumption and for final consumption. In this study the focus it put on the elements of the final consumption vector.

\section{Assessment of the structural differences in the values of the aggregated indicators between Bulgaria and the surveyed countries}

In the following presentation, in the tables, the results of the survey are presented on the degree of structural differences between Bulgaria and the surveyed countries on the basis of aggregated indicators.

The structural differences that exist between Bulgaria and each of the countries surveyed in terms of output produced in national economic systems are shown in Table 1.

Table 1. Structural differences of the final output indicator (2000-2013)

\begin{tabular}{|c|c|c|c|c|c|c|c|c|}
\hline \multicolumn{9}{|c|}{$\begin{array}{l}\text { Differentiation coefficients between Bulgaria and the countries surveyed by sectoral structure of the final } \\
\text { production for the period } 2000-2013\end{array}$} \\
\hline & Austria & Belgium & Denmark & Greece & Poland & Ireland & Slovakia & Slovenia \\
\hline 2000 & $9,73 \%$ & $13,80 \%$ & $14,31 \%$ & $26,32 \%$ & $10,59 \%$ & $18,68 \%$ & $17,44 \%$ & $13,72 \%$ \\
\hline 2001 & $8,61 \%$ & $11,92 \%$ & $15,25 \%$ & $26,87 \%$ & $8,87 \%$ & $15,53 \%$ & $16,77 \%$ & $12,53 \%$ \\
\hline 2002 & $8,35 \%$ & $12,85 \%$ & $13,62 \%$ & $23,60 \%$ & $8,41 \%$ & $15,81 \%$ & $18,25 \%$ & $13,50 \%$ \\
\hline 2003 & $7,45 \%$ & $11,28 \%$ & $15,63 \%$ & $23,85 \%$ & $7,15 \%$ & $12,96 \%$ & $17,64 \%$ & $12,16 \%$ \\
\hline 2004 & $7,78 \%$ & $8,76 \%$ & $17,75 \%$ & $27,44 \%$ & $5,15 \%$ & $12,90 \%$ & $14,39 \%$ & $6,88 \%$ \\
\hline 2005 & $6,16 \%$ & $8,26 \%$ & $15,90 \%$ & $26,02 \%$ & $5,03 \%$ & $13,02 \%$ & $13,56 \%$ & $6,44 \%$ \\
\hline 2006 & $6,16 \%$ & $7,67 \%$ & $16,39 \%$ & $26,34 \%$ & $5,04 \%$ & $14,76 \%$ & $13,40 \%$ & $6,32 \%$ \\
\hline 2007 & $5,96 \%$ & $7,64 \%$ & $17,65 \%$ & $26,46 \%$ & $5,39 \%$ & $14,50 \%$ & $15,24 \%$ & $5,97 \%$ \\
\hline 2008 & $11,47 \%$ & $11,11 \%$ & $14,25 \%$ & $27,87 \%$ & $5,86 \%$ & $25,99 \%$ & $16,92 \%$ & $4,99 \%$ \\
\hline 2009 & $11,98 \%$ & $13,95 \%$ & $22,58 \%$ & $28,84 \%$ & $5,80 \%$ & $20,75 \%$ & $18,08 \%$ & $9,42 \%$ \\
\hline 2010 & $9,84 \%$ & $9,65 \%$ & $27,41 \%$ & $11,10 \%$ & $6,05 \%$ & $17,60 \%$ & $17,66 \%$ & $8,32 \%$ \\
\hline 2011 & $9,43 \%$ & $10,18 \%$ & $25,24 \%$ & $12,32 \%$ & $6,17 \%$ & $16,89 \%$ & $17,94 \%$ & $8,75 \%$ \\
\hline 2012 & $9,94 \%$ & $9,86 \%$ & $21,45 \%$ & $11,54 \%$ & & $17,45 \%$ & $16,85 \%$ & $7,25 \%$ \\
\hline 2013 & $10,15 \%$ & & $20,72 \%$ & $11,01 \%$ & & & $16,02 \%$ & $6,18 \%$ \\
\hline
\end{tabular}

Source: Own table created on the basis of own calculations based on primary information provided by Eurostat 
At the beginning of the surveyed period (2000), the closest output to the total output of Bulgaria is the structure of Austria's final output - a difference of $9.73 \%$. Then the biggest difference in the volumes of the final output existed between Bulgaria and Greece $26.32 \%$.

The period under review is accompanied by a number of changes that have an impact on the development of national economies. This leads to corresponding changes in the coefficients of structural differences. At the end of the surveyed period, Bulgaria and Slovenia have the greatest proximity $-6.18 \%$, and the largest difference is between Bulgaria and Denmark $20.72 \%$

At the same time, according to the information provided, at the end of 2009 the highest coefficient of structural differences in the volume of the final output was also reported. This is the coefficient that characterizes the difference between Bulgaria and Greece $28.84 \%$.

As it was already mentioned, the volume of output produced in the economy and directed to consumption in the demographic system, is the main focus of the survey. When it comes to designing the end-output vector, it is needed to be mentioned that this element is particularly important. A main goal in the process of planning the future development of the Bulgarian economy should be the minimum differences between Bulgaria and the surveyed countries.

The information on the coefficients of structural differences is presented in Table 2.

Table 2. Coefficients of structural differences by volume of consumption indicator (2000-2013)

\begin{tabular}{|c|c|c|c|c|c|c|c|c|}
\hline \multicolumn{9}{|c|}{$\begin{array}{c}\text { Differentiation coefficients between Bulgaria and the countries surveyed by sectoral consumption patterns for } \\
\text { the period 2000-2013 }\end{array}$} \\
\hline & Austria & Belgium & Denmark & Greece & Poland & Ireland & Slovakia & Slovenia \\
\hline 2000 & $25,54 \%$ & $15,81 \%$ & $15,52 \%$ & $24,06 \%$ & $12,31 \%$ & $13,27 \%$ & $17,05 \%$ & $12,39 \%$ \\
\hline 2001 & $24,09 \%$ & $16,31 \%$ & $15,27 \%$ & $24,01 \%$ & $9,07 \%$ & $12,84 \%$ & $13,78 \%$ & $10,85 \%$ \\
\hline 2002 & $23,08 \%$ & $14,24 \%$ & $14,83 \%$ & $18,20 \%$ & $9,39 \%$ & $11,86 \%$ & $13,70 \%$ & $9,93 \%$ \\
\hline 2003 & $22,40 \%$ & $14,24 \%$ & $15,00 \%$ & $15,95 \%$ & $9,99 \%$ & $16,42 \%$ & $13,48 \%$ & $10,18 \%$ \\
\hline 2004 & $21,62 \%$ & $13,94 \%$ & $16,58 \%$ & $18,81 \%$ & $10,84 \%$ & $19,41 \%$ & $10,25 \%$ & $7,49 \%$ \\
\hline 2005 & $19,68 \%$ & $14,73 \%$ & $15,35 \%$ & $15,05 \%$ & $11,55 \%$ & $16,77 \%$ & $9,97 \%$ & $6,62 \%$ \\
\hline 2006 & $19,03 \%$ & $17,11 \%$ & $15,88 \%$ & $15,88 \%$ & $13,22 \%$ & $15,25 \%$ & $11,38 \%$ & $7,53 \%$ \\
\hline 2007 & $18,81 \%$ & $17,94 \%$ & $17,66 \%$ & $16,41 \%$ & $14,52 \%$ & $16,00 \%$ & $11,69 \%$ & $8,21 \%$ \\
\hline 2008 & $19,42 \%$ & $21,46 \%$ & $17,90 \%$ & $17,32 \%$ & $! 5,17 \%$ & $13,71 \%$ & $14,67 \%$ & $8,74 \%$ \\
\hline 2009 & $20,13 \%$ & $28,33 \%$ & $17,69 \%$ & $22,86 \%$ & $15,98 \%$ & $21,82 \%$ & $6,15 \%$ & $6,08 \%$ \\
\hline 2010 & $19,51 \%$ & $17,17 \%$ & $18,09 \%$ & $15,59 \%$ & $16,21 \%$ & $20,25 \%$ & $7,98 \%$ & $6,22 \%$ \\
\hline 2011 & $18,67 \%$ & $19,21 \%$ & $18,18 \%$ & $19,45 \%$ & $17,25 \%$ & $21,43 \%$ & $7,32 \%$ & $6,01 \%$ \\
\hline 2012 & $19,03 \%$ & $19,85 \%$ & $17,90 \%$ & $20,12 \%$ & $17,20 \%$ & $21,90 \%$ & $6,90 \%$ & $5,58 \%$ \\
\hline 2013 & $18,68 \%$ & $20,04 \%$ & & $18,40 \%$ & & $22,03 \%$ & $7,12 \%$ & $5,79 \%$ \\
\hline
\end{tabular}

Source: Own table created on the basis of own calculations based on primary information provided by Eurostat

At the beginning of the surveyed period (2000) the largest difference between Bulgaria and Austria, represented in percentage change, is $25.54 \%$. Poland is the country which volume of production for consumption by the demographic system is closest to that created in the Bulgarian economic system in 2000. The difference between the countries is $12.31 \%$.

At the end of the surveyed period, the closest volume to Bulgarian production for consumption is the volume of consumption output created in Slovenia's national economic system. The differences between the two countries are estimated at $5.79 \%$. In 2013, the largest distance (structural difference) between Bulgaria and Ireland is $22.03 \%$.

Almost identical at the end of the period are the values that characterize the differences between volume of the products for gross capital formation in Bulgaria and the same type of production in the other studied countries. At the end of 2013, the largest difference is between Bulgaria and Austria the distance between the two countries is $28.55 \%$. The closest result about the difference is measured in 2013 the volumes of production for gross capital formation of the economies of Bulgaria and Slovenia - 11.42\%. 
KALINKOVA S.

An interesting fact that should be noted is that before reaching this lowest value in the coefficient of structural differences between Bulgaria and Slovenia, at the beginning of the survey period (2000) a larger difference can be seen - $20.33 \%$. However, it is not the highest value in this starting year of the surveyed period when a difference of $37.06 \%$ between Bulgaria and Greece was recorded.

The data on the basis of which the conclusions are made is presented in Table 3 .

Table 3. Coefficients of structural differences by volume of production for gross capital formation $(2000-2013)$

\begin{tabular}{|c|c|c|c|c|c|c|c|c|}
\hline \multicolumn{9}{|c|}{$\begin{array}{l}\text { Differentiation coefficients between Bulgaria and the countries surveyed by structure of gross capital formation } \\
\text { for the period 2000-2013 }\end{array}$} \\
\hline & Austria & Belgium & Denmark & Greece & Poland & Ireland & Slovakia & Slovenia \\
\hline 2000 & $19,06 \%$ & $16,06 \%$ & $26,20 \%$ & $37,06 \%$ & $15,02 \%$ & $35,17 \%$ & $14,06 \%$ & $20,33 \%$ \\
\hline 2001 & $15,55 \%$ & $13,37 \%$ & $24,39 \%$ & $35,22 \%$ & $19,96 \%$ & $39,93 \%$ & $6,19 \%$ & $19,44 \%$ \\
\hline 2002 & $23,57 \%$ & $20,61 \%$ & $28,36 \%$ & $34,30 \%$ & $18,80 \%$ & $46,29 \%$ & $8,58 \%$ & $28,60 \%$ \\
\hline 2003 & $26,38 \%$ & $24,93 \%$ & $34,88 \%$ & $43,73 \%$ & $17,44 \%$ & $56,23 \%$ & $13,05 \%$ & $29,42 \%$ \\
\hline 2004 & $23,18 \%$ & $17,90 \%$ & $31,01 \%$ & $33,58 \%$ & $9,60 \%$ & $53,17 \%$ & $11,55 \%$ & $22,17 \%$ \\
\hline 2005 & $15,19 \%$ & $14,42 \%$ & $24,58 \%$ & $24,20 \%$ & $6,83 \%$ & $43,60 \%$ & $5,87 \%$ & $17,12 \%$ \\
\hline 2006 & $13,77 \%$ & $13,91 \%$ & $22,43 \%$ & $26,68 \%$ & $7,00 \%$ & $44,16 \%$ & $16,90 \%$ & $17,14 \%$ \\
\hline 2007 & $13,08 \%$ & $13,43 \%$ & $20,11 \%$ & $17,75 \%$ & $7,16 \%$ & $39,29 \%$ & $9,81 \%$ & $18,74 \%$ \\
\hline 2008 & $16,65 \%$ & $18,25 \%$ & $27,22 \%$ & $16,74 \%$ & $7,16 \%$ & $28,27 \%$ & $12,04 \%$ & $5,87 \%$ \\
\hline 2009 & $27,09 \%$ & $26,78 \%$ & $23,41 \%$ & $21,72 \%$ & $6,83 \%$ & $27,22 \%$ & $14,71 \%$ & $7,42 \%$ \\
\hline 2010 & $27,50 \%$ & $20,11 \%$ & $24,26 \%$ & $26,87 \%$ & $7,01 \%$ & $28,15 \%$ & $22,52 \%$ & $11,65 \%$ \\
\hline 2011 & $27,94 \%$ & $20,09 \%$ & $24,12 \%$ & $24,06 \%$ & $7,05 \%$ & $27,98 \%$ & $21,25 \%$ & $9,84 \%$ \\
\hline 2012 & $28,03 \%$ & $21,13 \%$ & $22,19 \%$ & $22,54 \%$ & & & $20,52 \%$ & $10,18 \%$ \\
\hline 2013 & $28,55 \%$ & $22,11 \%$ & $25,30 \%$ & $25,95 \%$ & & & $21,74 \%$ & $11,42 \%$ \\
\hline
\end{tabular}

Source: Own table created on the basis of own calculations based on primary information provided by Eurostat

Table 4. Coefficient of structural differences by indicator of expors (in the period 2000 - 2013)

\begin{tabular}{|c|c|c|c|c|c|c|c|c|}
\hline \multicolumn{9}{|c|}{$\begin{array}{l}\text { Differentiation coefficients between Bulgaria and the countries surveyed by sectoral export structure for the } \\
\text { period 2000-2013 }\end{array}$} \\
\hline & Austria & Belgium & Denmark & Greece & Poland & Ireland & Slovakia & Slovenia \\
\hline 2000 & $14,68 \%$ & $14,22 \%$ & $7,76 \%$ & $31,44 \%$ & $12,82 \%$ & $16,21 \%$ & $13,13 \%$ & $17,67 \%$ \\
\hline 2001 & $13,62 \%$ & $13,91 \%$ & $8,33 \%$ & $31,56 \%$ & $14,95 \%$ & $15,96 \%$ & $12,90 \%$ & $18,06 \%$ \\
\hline 2002 & $19,40 \%$ & $19,73 \%$ & $6,78 \%$ & $29,21 \%$ & $20,80 \%$ & $20,44 \%$ & $19,25 \%$ & $22,98 \%$ \\
\hline 2003 & $14,21 \%$ & $14,89 \%$ & $8,55 \%$ & $37,12 \%$ & $15,76 \%$ & $15,57 \%$ & $15,84 \%$ & $17,97 \%$ \\
\hline 2004 & $8,13 \%$ & $10,50 \%$ & $12,48 \%$ & $46,80 \%$ & $13,03 \%$ & $13,43 \%$ & $12,11 \%$ & $11,97 \%$ \\
\hline 2005 & $6,22 \%$ & $6,98 \%$ & $19,18 \%$ & $50,02 \%$ & $9,48 \%$ & $14,94 \%$ & $8,64 \%$ & $8,63 \%$ \\
\hline 2006 & $6,12 \%$ & $5,99 \%$ & $23,46 \%$ & $44,55 \%$ & $8,11 \%$ & $18,87 \%$ & $8,09 \%$ & $8,12 \%$ \\
\hline 2007 & $6,10 \%$ & $5,86 \%$ & $26,58 \%$ & $48,82 \%$ & $6,80 \%$ & $20,98 \%$ & $8,44 \%$ & $7,12 \%$ \\
\hline 2008 & $6,52 \%$ & $5,92 \%$ & $27,79 \%$ & $52,12 \%$ & $6,49 \%$ & $33,43 \%$ & $8,26 \%$ & $5,83 \%$ \\
\hline 2009 & $8,30 \%$ & $7,71 \%$ & $21,40 \%$ & $44,44 \%$ & $6,76 \%$ & $29,35 \%$ & $16,82 \%$ & $10,86 \%$ \\
\hline 2010 & $7,84 \%$ & $6,97 \%$ & $19,58 \%$ & $11,43 \%$ & $5,39 \%$ & $28,94 \%$ & $16,86 \%$ & $10,19 \%$ \\
\hline 2011 & $7,92 \%$ & $7,15 \%$ & $20,94 \%$ & $21,54 \%$ & & $29,17 \%$ & $17,43 \%$ & $10,27 \%$ \\
\hline 2012 & $7,31 \%$ & $8,92 \%$ & & $18,40 \%$ & & & $16,59 \%$ & $9,60 \%$ \\
\hline 2013 & $7,45 \%$ & $7,77 \%$ & & $15,38 \%$ & & & $18,93 \%$ & $9,85 \%$ \\
\hline
\end{tabular}

Source: Own table created on the basis of own calculations based on primary information provided by Eurostat 
Export as an element of the final output vector of the input-output tables should be explored too. At the beginning of the surveyed period (2000), the closeness of the total export volume between Bulgaria and Denmark is greatest, with a structural difference of $7.76 \%$. At the same time, the highest value coefficient that describes the differences in the volume of exports is between Bulgaria and Greece $31.44 \%$. This coefficient between the two countries keeps a high trend throughout the whole surveyed period.

According to the latest published data, the export volumes of the national economic systems of Bulgaria and Austria are the most structurally closest. The coefficient of structural difference for this indicator between the two countries is $7.45 \%$. At the end of the surveyed period (2013) the largest differences in the volume of export $(15.38 \%)$ is recorded between Bulgaria and Slovakia (Table 4).

The coefficients of structural differences between Bulgaria and the surveyed countries in the period 2000 - 2013 based on the value added for each national economic system are presented in Table 5 of this study.

Table 5. Coefficients of structural differences by value added indicator (2000-2013)

\begin{tabular}{|c|c|c|c|c|c|c|c|c|}
\hline \multicolumn{9}{|c|}{$\begin{array}{l}\text { Differentiation coefficients between Bulgaria and the countries surveyed by the sectoral value added structur: } \\
\text { for the period } 2000-2013\end{array}$} \\
\hline & Austria & Belgium & Denmark & Greece & Poland & Ireland & Slovakia & Slovenia \\
\hline 2000 & $30,33 \%$ & $33,04 \%$ & $32,08 \%$ & $38,65 \%$ & $26,13 \%$ & $25,05 \%$ & $18,78 \%$ & $21,87 \%$ \\
\hline 2001 & $28,78 \%$ & $32,88 \%$ & $32,42 \%$ & $38,46 \%$ & $25,59 \%$ & $21,89 \%$ & $17,79 \%$ & $21,76 \%$ \\
\hline 2002 & $28,19 \%$ & $31,84 \%$ & $6,78 \%$ & $39,57 \%$ & $25,75 \%$ & $21,30 \%$ & $16,13 \%$ & $20,58 \%$ \\
\hline 2003 & $28,41 \%$ & $33,06 \%$ & $32,96 \%$ & $42,33 \%$ & $23,27 \%$ & $23,01 \%$ & $17,73 \%$ & $20,67 \%$ \\
\hline 2004 & $32,41 \%$ & $36,26 \%$ & $32,12 \%$ & $41,38 \%$ & $19,93 \%$ & $24,28 \%$ & $20,20 \%$ & $22,81 \%$ \\
\hline 2005 & $31,12 \%$ & $35,77 \%$ & $25,53 \%$ & $34,66 \%$ & $14,09 \%$ & $20,55 \%$ & $17,51 \%$ & $21,97 \%$ \\
\hline 2006 & $30,76 \%$ & $36,21 \%$ & $23,89 \%$ & $33,45 \%$ & $13,77 \%$ & $19,66 \%$ & $20,27 \%$ & $22,35 \%$ \\
\hline 2007 & $30,78 \%$ & $36,05 \%$ & $23,40 \%$ & $33,30 \%$ & $12,65 \%$ & $16,73 \%$ & $19,94 \%$ & $22,84 \%$ \\
\hline 2008 & $27,05 \%$ & $36,20 \%$ & $25,05 \%$ & $38,50 \%$ & $12,24 \%$ & $21,08 \%$ & $22,04 \%$ & $16,77 \%$ \\
\hline 2009 & $31,10 \%$ & $45,70 \%$ & $41,04 \%$ & $38,01 \%$ & $10,63 \%$ & $21,05 \%$ & $10,84 \%$ & $11,30 \%$ \\
\hline 2010 & $28,75 \%$ & $32,80 \%$ & $39,84 \%$ & $38,32 \%$ & $10,39 \%$ & $21,92 \%$ & $14,61 \%$ & $11,21 \%$ \\
\hline 2011 & $27,45 \%$ & $30,25 \%$ & $37,40 \%$ & $39,48 \%$ & & $20,17 \%$ & $15,18 \%$ & $9,31 \%$ \\
\hline 2012 & $26,17 \%$ & $32,29 \%$ & & $37,13 \%$ & & & $16,59 \%$ & $10,32 \%$ \\
\hline 2013 & $27,29 \%$ & $31,50 \%$ & & $35,27 \%$ & & & $16,42 \%$ & $9,65 \%$ \\
\hline
\end{tabular}

Source: Own table created on the basis of own calculations based on primary information provided by Eurostat

The data shows that at the beginning of the surveyed period the differences between Bulgaria and Greece are the highest $-36.85 \%$, a trend that remained throughout the surveyed period. Thus, in 2013 (the last year of the survey period), the differences are described with a value of $35.27 \%$.

The closeness of the coefficient of structural differences in value added in 2000 is between Bulgaria and Slovakia - $18.78 \%$. This gap melts to $16.42 \%$ in 2013. However, in 2013 the smallest structural difference is between Bulgaria and Slovenia - 9.65\%.

The structural differences between Bulgaria and the surveyed countries in relation to the direct material costs for the production of a unit of total production in the period 20002013 are presented in Table 6.

The closest is the proximity to the amount of direct material costs in 2000 between Bulgaria and Slovenia. The coefficient of structural differences is $9.32 \%$. Although with some hesitation, in 2013 there is again the closest proximity between the two countries. Differences are estimated at $9.51 \%$. The biggest difference at the beginning of the survey period is between Bulgaria and Ireland - $28.11 \%$. This tendency persists throughout the surveyed period, and at the end the coefficient of structural differences between the two countries is $28.98 \%$. 
KALINKOVA S.

Table 6. Coefficients of structural differences by direct material costs ratio for the first total output (2000-2013)

Differentiation coefficients between Bulgaria and the countries surveyed by sectoral structure of direct material costs for the first total output for the period 2000-2013

\begin{tabular}{|c|c|c|c|c|c|c|c|c|}
\hline & Austria & Belgium & Denmark & Greece & Poland & Ireland & Slovakia & Slovenia \\
\hline 2000 & $20,99 \%$ & $14,84 \%$ & $20,36 \%$ & $25,30 \%$ & $20,51 \%$ & $28,11 \%$ & $13,46 \%$ & $9,32 \%$ \\
\hline 2001 & $19,73 \%$ & $14,69 \%$ & $19,43 \%$ & $24,60 \%$ & $23,51 \%$ & $25,57 \%$ & $13,75 \%$ & $10,79 \%$ \\
\hline 2002 & $19,65 \%$ & $16,61 \%$ & $18,44 \%$ & $23,30 \%$ & $25,89 \%$ & $23,12 \%$ & $13,41 \%$ & $13,87 \%$ \\
\hline 2003 & $21,54 \%$ & $17,34 \%$ & $20,39 \%$ & $26,50 \%$ & $23,47 \%$ & $23,95 \%$ & $13,61 \%$ & $14,52 \%$ \\
\hline 2004 & $19,88 \%$ & $14,55 \%$ & $20,64 \%$ & $27,60 \%$ & $20,68 \%$ & $27,13 \%$ & $11,54 \%$ & $12,80 \%$ \\
\hline 2005 & $21,45 \%$ & $14,16 \%$ & $21,68 \%$ & $30,20 \%$ & $16,34 \%$ & $26,41 \%$ & $12,89 \%$ & $13,01 \%$ \\
\hline 2006 & $22,36 \%$ & $16,38 \%$ & $22,53 \%$ & $31,80 \%$ & $15,65 \%$ & $22,59 \%$ & $14,25 \%$ & $13,53 \%$ \\
\hline 2007 & $23,35 \%$ & $17,43 \%$ & $22,85 \%$ & $33,20 \%$ & $15,11 \%$ & $24,69 \%$ & $15,63 \%$ & $14,05 \%$ \\
\hline 2008 & $20,01 \%$ & $16,00 \%$ & $37,13 \%$ & $31,40 \%$ & $13,12 \%$ & $30,00 \%$ & $10,26 \%$ & $12,12 \%$ \\
\hline 2009 & $22,91 \%$ & $19,80 \%$ & $37,13 \%$ & $34,00 \%$ & $13,82 \%$ & $28,67 \%$ & $15,75 \%$ & $14,25 \%$ \\
\hline 2010 & $19,95 \%$ & $14,74 \%$ & $36,92 \%$ & $20,30 \%$ & $13,71 \%$ & $26,63 \%$ & $14,73 \%$ & $10,65 \%$ \\
\hline 2011 & $20,74 \%$ & $14,72 \%$ & $34,97 \%$ & $27,52 \%$ & & $26,98 \%$ & $14,12 \%$ & $10,72 \%$ \\
\hline 2012 & $20,32 \%$ & $14,12 \%$ & & $26,93 \%$ & & & $15,25 \%$ & $9,43 \%$ \\
\hline 2013 & $20,02 \%$ & $14,23 \%$ & & $27,17 \%$ & & & $15,48 \%$ & $9,51 \%$ \\
\hline
\end{tabular}

Source: Own table created on the basis of own calculations based on primary information provided by Eurostat

Regarding the proximity between Bulgaria and the surveyed countries in terms of full material production units, production costs, the closest proximity to the economies of Bulgaria and Slovenia over the whole of the surveyed period. In 2000, the structural difference between the two countries was $5.42 \%$ and in $20135.86 \%$. The largest in 2000 were the structural differences between Bulgaria and Greece $(17.11 \%)$, decreasing to $18.34 \%$.

Table 7. Coefficient of structural differences for the indicator total material costs per unit of output (in the period $2000-2013)$

Differentiation coefficients between Bulgaria and the countries surveyed by sectoral structure of full material costs for the 1st final production for the period 2000-2013

\begin{tabular}{|c|c|c|c|c|c|c|c|c|}
\hline \multicolumn{9}{|c|}{ costs for the 1st final production for the period $2000-2013$} \\
\hline & Austria & Belgium & Denmark & Greece & Poland & Ireland & Slovakia & Slovenia \\
\hline 2000 & $12,99 \%$ & $8,89 \%$ & $10,87 \%$ & $17,11 \%$ & $12,19 \%$ & $15,72 \%$ & $9,52 \%$ & $5,42 \%$ \\
\hline 2001 & $11,54 \%$ & $8,75 \%$ & $9,96 \%$ & $32,72 \%$ & $15,38 \%$ & $14,26 \%$ & $8,19 \%$ & $6,02 \%$ \\
\hline 2002 & $10,69 \%$ & $9,88 \%$ & $9,32 \%$ & $14,77 \%$ & $16,63 \%$ & $12,59 \%$ & $7,87 \%$ & $8,22 \%$ \\
\hline 2003 & $12,12 \%$ & $9,78 \%$ & $10,85 \%$ & $17,24 \%$ & $14,46 \%$ & $13,16 \%$ & $6,98 \%$ & $8,24 \%$ \\
\hline 2004 & $11,97 \%$ & $7,95 \%$ & $11,50 \%$ & $18,73 \%$ & $13,10 \%$ & $15,01 \%$ & $4,75 \%$ & $7,02 \%$ \\
\hline 2005 & $14,40 \%$ & $7,94 \%$ & $13,66 \%$ & $21,96 \%$ & $10,17 \%$ & $16,43 \%$ & $6,75 \%$ & $8,74 \%$ \\
\hline 2006 & $16,80 \%$ & $20,09 \%$ & $5,90 \%$ & $23,12 \%$ & $6,42 \%$ & $10,44 \%$ & $4,62 \%$ & $15,57 \%$ \\
\hline 2007 & $16,85 \%$ & $10,95 \%$ & $15,90 \%$ & $25,05 \%$ & $10,24 \%$ & $16,72 \%$ & $9,65 \%$ & $10,87 \%$ \\
\hline 2008 & $12,16 \%$ & $8,63 \%$ & $18,93 \%$ & $21,70 \%$ & $11,92 \%$ & $17,72 \%$ & $5,95 \%$ & $7,67 \%$ \\
\hline 2009 & $13,62 \%$ & $11,23 \%$ & $11,11 \%$ & $22,51 \%$ & $10,59 \%$ & $16,70 \%$ & $8,64 \%$ & $9,04 \%$ \\
\hline 2010 & $11,03 \%$ & $7,70 \%$ & $12,04 \%$ & $11,79 \%$ & $11,02 \%$ & $16,06 \%$ & $9,68 \%$ & $6,22 \%$ \\
\hline 2011 & $12,05 \%$ & $9,47 \%$ & $12,94 \%$ & $17,43 \%$ & $11,95 \%$ & $16,26 \%$ & $10,36 \%$ & $6,49 \%$ \\
\hline 2012 & $12,42 \%$ & $9,18 \%$ & $11,74 \%$ & $15,69 \%$ & & & $10,94 \%$ & $5,39 \%$ \\
\hline 2013 & $11,97 \%$ & $8,32 \%$ & & $18,34 \%$ & & & $10,53 \%$ & $5,86 \%$ \\
\hline
\end{tabular}

Source: Own table created on the basis of own calculations based on primary information provided by Eurostat

\section{CONCLUSION}

On the basis of the survey, the coefficients of structural differences between Bulgaria and the surveyed countries in each of the studied areas are obtained as a final result. The interpretation of these coefficients gives basis for outlining 
the tendency of convergence between Bulgaria and a significant part of the studied countries. In terms of product output, there is convergence with all countries (except Denmark). The highest degree of proximity in the surveyed period exists between Bulgaria and Slovenia.

The outlined trend should be assessed not only from the point of view of the structural differences which are studied and presented here. As a direction for future research in the area, there is also a need to assess the proximity of the country's final production both in quantitative and qualitative terms. And, in particular, whether, this convergence of structures is also an approximation between the output, consumed by the inhabitants of these countries in terms of volume and quality.

Significantly higher are the structural differences related to gross capital formation. And in this case the tendency towards convergence is expressed, but we also have to answer the question, "What a useful result is created with the capital investments that are made in the different periods of time?" Regarding the structure of the export vector, the greatest convergence is observed between Bulgaria and Austria. In this case, the assessment is rather partial, because no conclusions can be drawn from the data on the quantities of production that generate this vector and the quality of this production. Within the framework of the present study, it is also not possible to assess the main partners to which exports are directed, as well as the degree of stability of the relations built.

Value added as an indicator that characterizes the beneficial result generated in an economy is also of particular importance in its assessment. Over the period under review there is a very slow tendency towards convergence between Bulgaria and other countries (except Slovenia). This tendency can be assessed as worrying (negative), especially by looking at it in parallel with the significantly closer export structure and the structure of the total output of the economy. Analyzed information leads to the conclusion that it is necessary to look for approaches to increase resource efficiency (leading to reduced production costs). It is only in efficiency and productivity that convergence can be achieved between Bulgaria and other countries and in terms of the added value indicator.

This conclusion is also confirmed by the direct and full material costs for the period under review. And there is a tendency towards convergence between Bulgaria and the studied countries. However, with regard to these indicators, further research is needed to better outlining the cost with which each economic sector produces a unit of its output.

In conclusion, it can be said that the research carried out is a kind of starting point, which sets the direction for the necessary future research in the field.

\section{REFERENCES}

1. Sugarev, Z., Demografska statistika, izd. Nauka i izkustvo, S., 1974, pp. 106, 107

2. Minasyan, G., Izmervane $i$ analiz na strukturnata dinamika, Statistika, 1980, №2

3. Gatev, K., Metodi za statistcheski analiz na ikonomicheski i socialni strukturi, izd. Nauka i izkustvo, S., 1987

4. Gatev, K., Metodi za statistcheski analiz na ikonomicheski i socialni strukturi, izd. Nauka i izkustvo, S., 1987, p. 74 